\title{
Thioredoxin-interacting protein mediates dysfunction of tubular autophagy in diabetic kidneys through inhibiting autophagic flux
}

\author{
Chunling Huang ${ }^{1,2}$, Mike Z Lin ${ }^{1}$, Delfine Cheng ${ }^{3}$, Filip Braet ${ }^{3,4}$, Carol A Pollock ${ }^{1}$ and Xin-Ming Chen ${ }^{1}$
}

Thioredoxin-interacting protein (TXNIP) expression is ubiquitous and is induced by a variety of cellular stresses, including high intracellular glucose. TXNIP is associated with activation of oxidative stress and tubulointerstitial fibrosis in diabetic nephropathy. Autophagy is a major pathway that delivers damaged proteins and organelles to lysosomes to maintain cellular homeostasis. This study aimed to investigate the dysregulation of autophagy and the regulation of TXNIP on autophagy in renal proximal tubular cells (PTCs) under diabetic conditions. The formation of autophagosomes was measured using transmission electron microscopy, and LC3-II, and the effectiveness of autophagic clearance was determined by p62 expression in diabetic kidney and in human PTCs exposed to high glucose (HG). The results collectively demonstrated increased expression of TXNIP, LC3/LC3-II and p62 in renal tubular cells of mice with diabetic nephropathy and in cultured human PTCs exposed to HG $(30 \mathrm{mM} / \mathrm{l})$ for $48 \mathrm{~h}$ compared with control. The formation of autophagic vacuoles was increased in HG-induced cells. Furthermore, silencing of TXNIP by siRNA transfection reduced autophagic vacuoles and the expression of LC3-II and p62 in human PTCs exposed to HG compared with control and partially reversed the accumulation of LC3-II and p62 induced by bafilomycin $A_{1}(50 \mathrm{nM} / \mathrm{l})$, a pharmacological inhibitor of autophagy which blocks the fusion of autophagosomes with lysosomes and impairs the degradation of LC3-II and p62. Collectively, these results suggest that hyperglycemia leads to dysfunction of autophagy in renal tubular cells and decreases autophagic clearance. HG-induced overexpression of TXNIP may contribute to the dysfunction of tubular autophagy in diabetes.

Laboratory Investigation (2014) 94, 309-320; doi:10.1038/labinvest.2014.2; published online 3 February 2014

KEYWORDS: autophagy; autophagy flux; diabetic nephropathy; renal proximal tubular cells; thioredoxin-interacting protein

Autophagy is a lysosomal protein degradation pathway. It is initiated by the formation of double-membrane-bound vesicles called autophagosomes, which are formed from cup-shaped structures known as phagophores. ${ }^{1}$ There are four key stages involving the autophagy pathway: initiation, elongation, maturation, and fusion with the lysosomes. ${ }^{1}$ At the last stage, the autophagosomes merge with the lysosomal compartment to form autolysosomes. ${ }^{1}$ Autophagic flux is an indicator that the autophagy process has been completed. This catabolic process normally functions in all the cells and has a crucial role in removing protein aggregates as well as damaged or excess organelles to maintain intracellular homeostasis and cell integrity. Hence, autophagy primarily exerts a protective role under physiological conditions and ensures cell survival under stress conditions. Renal tubular cell autophagy is known to be renoprotective in acute kidney injury induced by ischemia-reperfusion injury. ${ }^{2-4}$ Constitutive and induced autophagy is a major protective mechanism against podocyte aging and glomerular injury. ${ }^{5}$ Moreover, autophagy dysregulation is associated with intracellular stresses that are inherent in diabetes mellitus. It has been reported that high glucose (HG)-induced defective autophagy in podocytes facilitates podocyte injury. ${ }^{6}$ Hence, it has been hypothesized that defective autophagy may accelerate the progression of diabetic nephropathy. ${ }^{6}$ Despite the critical recognition of tubulointerstitial pathology in progressive renal disease, and the critical

\footnotetext{
${ }^{1}$ Kolling Institute of Medical Research, Sydney Medical School, University of Sydney, Royal North Shore Hospital, St Leonards, NSW, Australia; ${ }^{2}$ Xiamen Center of Clinical Laboratory, Xiamen Zhongshan Hospital, Medical College of Xiamen University, Xiamen, China; ${ }^{3}$ School of Medical Sciences (Discipline of Anatomy and Histology) — The Bosch Institute, University of Sydney, Sydney, NSW, Australia and ${ }^{4}$ Australian Centre for Microscopy and Microanalysis, University of Sydney, Sydney, NSW, Australia Correspondence: Professor CA Pollock, MBBS, PhD, Department of Medicine, Professorial Suite, Level 7, Kolling Building, Royal North Shore Hospital, St Leonards, NSW 2065, Australia. E-mail carol.pollock@sydney.edu.au
} 
involvement of the renal proximal tubular cell (PTC) in the pathogenesis of diabetic nephropathy, ${ }^{7,8}$ the role of tubular autophagy in diabetic nephropathy has not been defined.

Hyperglycemia leads to the activation of oxidative stress and increased production of reactive oxygen species (ROS), which in turn results in tubular cell injury and deposition of extracellular matrix proteins in the tubulointerstitium. ${ }^{9-12}$ Thioredoxin-interacting protein (TXNIP) is a negative regulator of thioredoxin function, inhibiting its reducing capacity ${ }^{13}$ and promoting cellular oxidative stress. TXNIP expression is ubiquitous and is induced by a variety of cellular stresses, including high intracellular glucose. ${ }^{14}$ TXNIP overexpression renders cells more susceptible to oxidative stress and promotes apoptosis ${ }^{15}$ and excessive matrix production, key factors in the development of tubulointerstitial fibrosis. ${ }^{16,17}$ We have previously demonstrated that TXNIP is the gene most significantly upregulated in human proximal tubule cells exposed to $\mathrm{HG}^{18}$ a finding confirmed in kidneys of diabetic mice and subsequently in humans with diabetic nephropathy. ${ }^{19,20}$
The present study was performed to investigate the dysregulation of tubular autophagy in diabetic nephropathy. We initially examined the formation of autophagosomes in an established mouse model of diabetic nephropathy by measuring the expression of microtubule-associated protein 1 light chain 3 phospholipid-conjugated form (LC3-II), which is specifically localized to autophagic structures throughout the autophagy process from phagophore to lysosomal degradation. ${ }^{21,22}$ The formation of autophagosomes was also confirmed in cultured kidney tubular cell exposed to HG using transmission electron microscope. Autophagic clearance was examined by measuring the expression of sequestosome1 (p62) in this mouse model. Then we defined the role of TXNIP on tubular autophagy using TXNIP siRNA transfection in PTCs exposed to HG. Our data clearly demonstrate dysfunction of tubular autophagy under HG conditions in vitro and in a mouse model of diabetic nephropathy. Furthermore, our results clearly suggest that HG-induced overexpression of TXNIP in tubular cells contributes to the impairment of autophagic flux. a
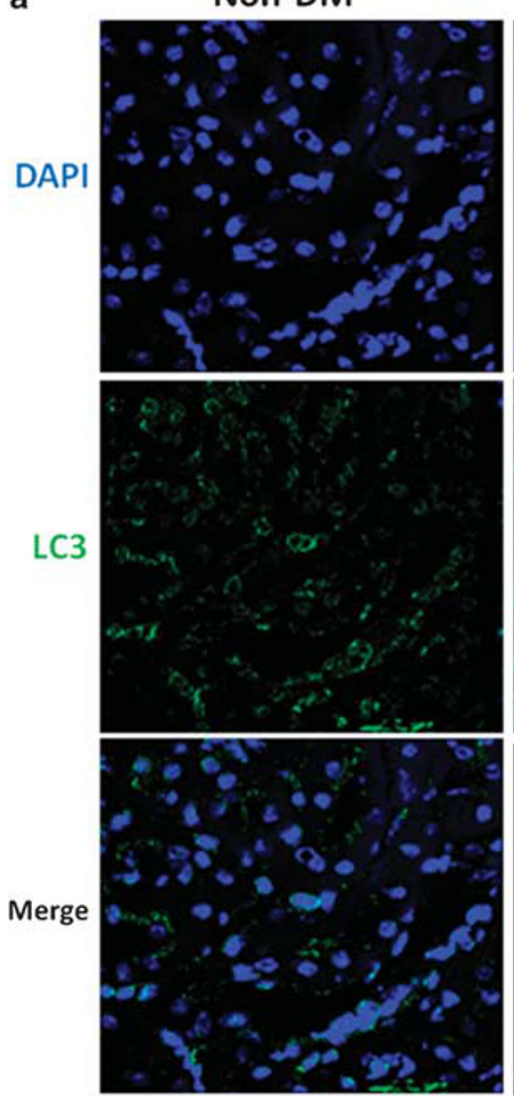

DM

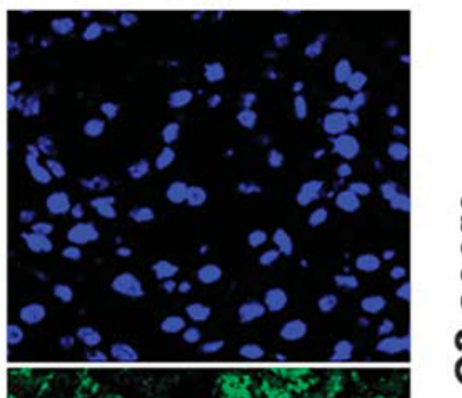

b

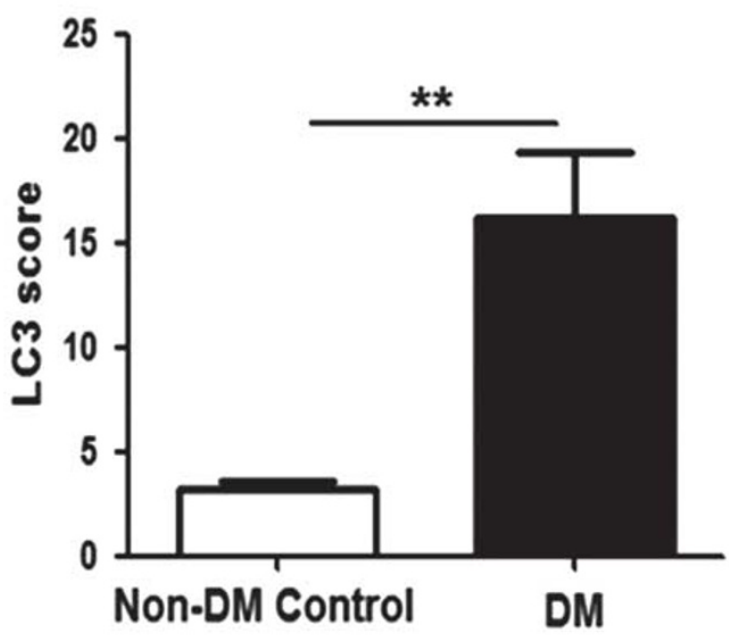

Figure 1 The expression of LC3 in STZ-induced diabetic mice. C57B/6 mice were injected with STZ to induce diabetes or citrate buffer alone as nondiabetic control. After 24 weeks diabetes, kidney tissues were collected for immnostaining. (a) Immunofluorescence staining of LC3 in mice kidney tissues. (b) Quantification of LC3 expression in mice kidney tissues. Results are presented as mean + s.e.m. ${ }^{* *} P<0.01$. $N=8$. Original magnification: $\times 600$. 


\section{MATERIALS AND METHODS \\ Materials}

Anti-LC3-B and p62 antibodies were purchased from Abcam (Cambridge, MA), anti- $\alpha$-tubulin antibody and bafilomycin A1 were from Sigma (St Louis, MO), and anti-nitrotyrosine antibody was from Millipore (Darmstadt, Germany). AntiTXNIP and Alexa488-conjugated secondary antibodies were obtained from Invitrogen (Carlsbad, CA).

\section{Animal Studies}

Eight-week-old male C57B/6 mice (Jackson laboratory, ME) weighing approximately 20-25g were assigned to receive either $55 \mathrm{mg} / \mathrm{kg}$ of streptozotocin (STZ) (Sigma, MO) diluted in $0.1 \mathrm{M}$ citrate buffer, $\mathrm{pH} 4.5$, or citrate buffer alone by intraperitoneal injection as described previously. ${ }^{23}$ A group of $\mathrm{C} 57 \mathrm{~B} / 6$ mice $(n=8)$ received citrate buffer alone served as non-diabetic controls. All animals were housed in the Kearns Animal Facility of Kolling Institute of Medical Research with a stable environment maintained at $22 \pm 1{ }^{\circ} \mathrm{C}$ with a $12 / 12-\mathrm{h}$ light-dark cycle.

Mice were weighed, and their blood glucose levels were measured using the Accu-chek glucometer (Roche Diag- nostics) weekly, and only STZ-treated animals with blood glucose $>16 \mathrm{mmol} / \mathrm{l}$ were considered diabetic. After animals were culled, left kidneys were removed and snap frozen for the isolation of RNA or protein, and right kidneys were perfused with PBS and fixed in 10\% buffered formalin for histological examination.

This study was carried out in strict accordance with the recommendations in the Guide of the National Health and Medical Research Council of Australia's Code for the Care and Use of Animals for Scientific Purposes. The protocol was approved by the Animal Research Ethics Committee of Royal North Shore Hospital (Permit Number: 1101-001A). All surgery was performed under sodium pentobarbital anesthesia, and all efforts were made to minimize suffering.

\section{Histology and Immunostaining}

Frozen tissues were fixed in ice-cold acetone for $10 \mathrm{~min}$ and then washed twice with ice-cold PBS. After pre-incubation with $2 \%$ BSA in PBS for $1 \mathrm{~h}$, the tissues were incubated with primary antibodies anti-rabbit-LC3 (1:200) and anti-rabbitp62 (1:100) for $1 \mathrm{~h}$ at room temperature. After washing with PBS, cells were incubated with secondary anti-rabbit Alexa a

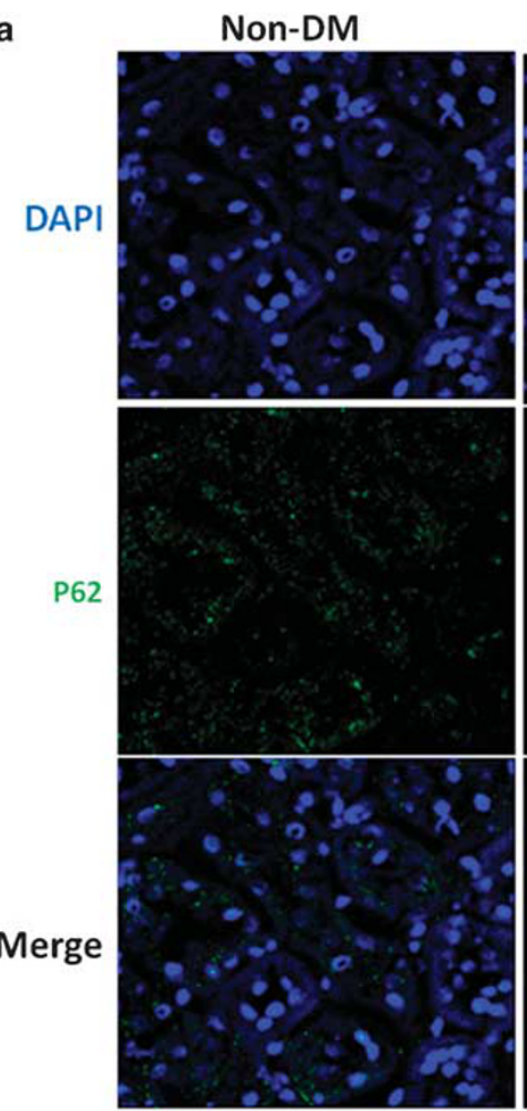

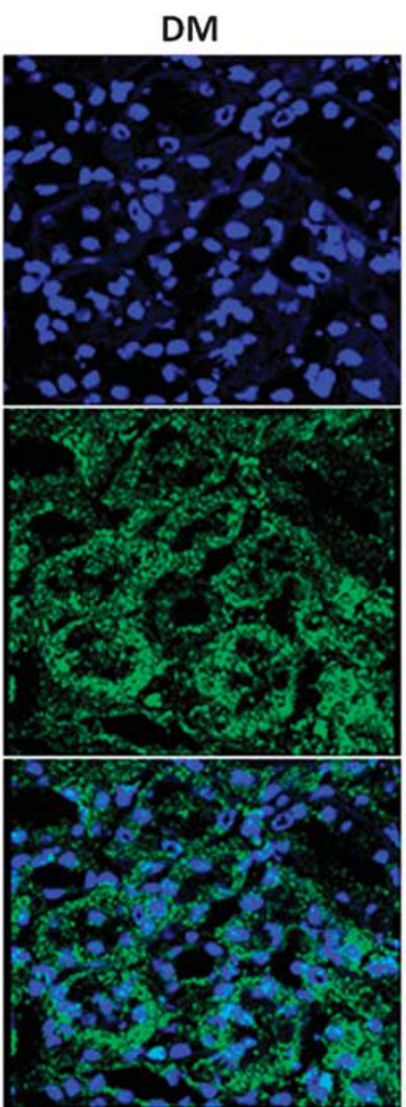

b

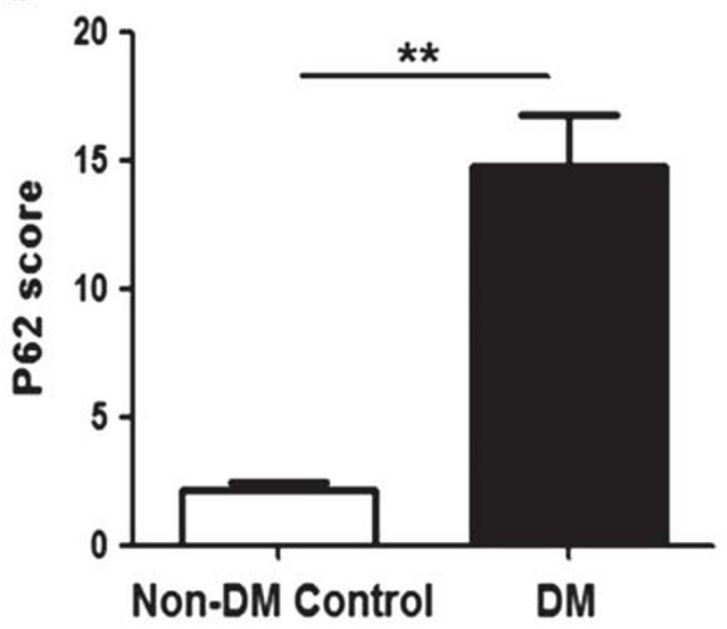

Figure 2 The expression of p62 in STZ-induced diabetic mice. C57B/6 mice were injected with STZ to induce diabetes or citrate buffer alone as nondiabetic control. After 24 weeks diabetes, kidney tissues were collected for immnostaining. (a) Immunofluorescence staining of p62 in mice kidney tissues. (b) Quantification of p62 expression in mice kidney tissues. Results are presented as mean + s.e.m. ${ }^{* *} P<0.01 . N=8$. Original magnification: $\times 600$. 
Fluor-488 (1:1000, Invitrogen) for $40 \mathrm{~min}$ at room temperature. Cells were then washed with PBS and counterstained with 4', 6-diamidino-2 phenylindole (DAPI)-mounting medium (Invitrogen). The immunofluorescence images were collected by confocal fluorescence microscopy (Leica Microsystems, Mannheim, Germany).

Paraffin-embedded kidney sections were used for immunohistochemical staining. Briefly, after heat retrieval, endogenous peroxidase activity was blocked by incubation in $0.3 \%$ hydrogen peroxide. After pre-incubation with $10 \%$ protein block (Dako, CA) for 10 min at room temperature to block nonspecific binding of antibodies, the tissues were incubated overnight at $4{ }^{\circ} \mathrm{C}$ with primary antibodies against anti-rabbitTXNIP (1:400) and anti-rabbit-nitrotyrosine (1:900). After incubation with appropriate secondary antibodies, sections were developed with 3,3-diaminobenzidine (Dako, CA) to produce a brown color and counterstained with hematoxylin. Positive signals in the renal cortex regions were quantified using Image J software as previously described. ${ }^{24}$

\section{Cell Culture and TXNIP Gene Silencing}

Immortalized human PTCs (HK2 cells) were obtained from ATCC (Manassas, VA). HK2 cells were grown in keratinocyte serum-free media medium (Invitrogen, CA) and used for experiment at passages $10-15$.

HK2 cells were transfected with either siRNA targeting TXNIP or negative control siRNA using Lipofectamine 2000 reagent (Invitrogen, CA) according to the manufacturer's instructions. The targeting siRNA sequence for TXNIP is $5^{\prime}$-CAUCCUUCGAGUUGAAUAUTT- ${ }^{\prime}$ (GenePharma, Shanghai). After transfection overnight, the cells were incubated with HG $(30 \mathrm{mM})$ for $48 \mathrm{~h}$, then cell lysates and total RNA were collected for further analysis, or cells were pretreated with $50 \mathrm{nmol} / \mathrm{l}$ bafilomycin $\mathrm{A}_{1}$ for $3 \mathrm{~h}$ and then incubated with HG $(30 \mathrm{mM})$ for $48 \mathrm{~h}$.

\section{The Measurement of Autophagy Using Transmission Electron Microscopy}

HK2 cells grown on glass coverslip were transfected with TXNIP or scramble siRNA overnight and then incubated with HG $(30 \mathrm{mM} / \mathrm{l})$ for $48 \mathrm{~h}$ as described above. The samples were prepared for transmission electron microscopic analysis as reported previously. ${ }^{25,26}$ Briefly, cells were washed with pre-warmed PBS twice, and then fixed in $2 \%$ glutaraldehyde in PBS for $60 \mathrm{~min}$ at room temperature. Fixed cells were washed with PBS three times and then postfixed with $1 \%$ in
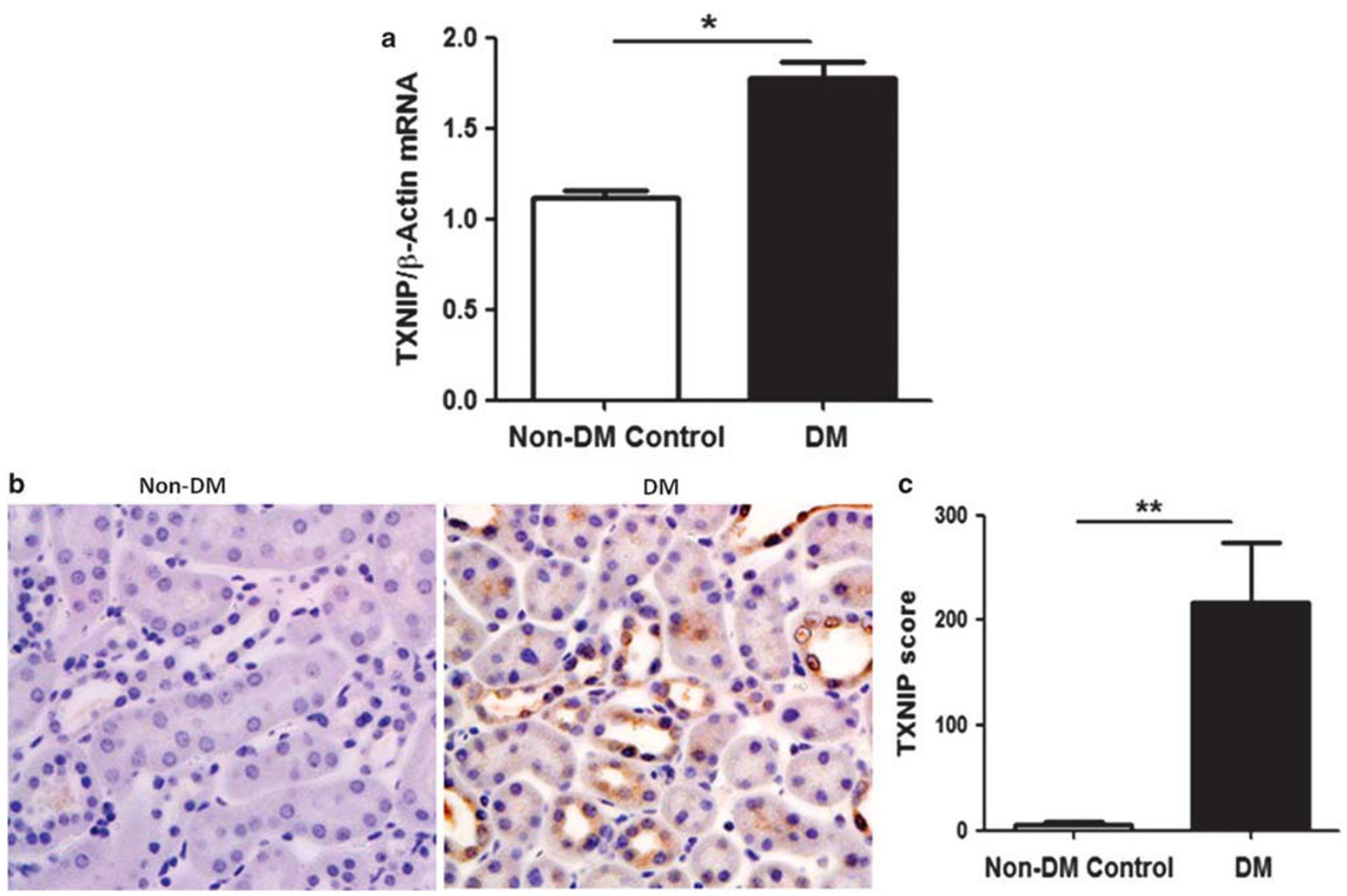

Figure 3 The mRNA and protein expression of TXNIP in diabetic mice. C57B/6 mice were injected with STZ to induce diabetes or citrate buffer alone as non-diabetic control. After 24 weeks diabetes, kidney tissues were collected for RNA isolation and immnostaining. (a) Quantitative RT-PCR mRNA expression of TXNIP in mice kidney tissues. (b) Immunohistochemical staining of TXNIP in mice kidney tissues. (c) Quantification of TXNIP expression in mice kidney tissues. Results are presented as mean \pm s.e.m. ${ }^{*} P<0.05$ and ${ }^{* *} P<0.01 . N=8$. Original magnification: $\times 600$. 
osmium tetroxide in PBS for $1 \mathrm{~h}$. After rinsing three times with distilled water, the samples were further stained with $1 \%$ tannic acid for $1 \mathrm{~h}$. Finally, the cells were infiltrated and double-embedded in Epon. Sections of $70 \mathrm{~nm}$ were generated with an ultramicrotome (Ultracut 7, Leica). The specimens were examined with the JEOL $2100 \mathrm{TEM}$ at $200 \mathrm{kV}$.

\section{RNA Isolation and RT-PCR Analysis}

Total RNA was extracted from cells and mouse kidneys using GenElute Mammalian Total RNA Miniprep Kit (Sigma) or Trizol (Invitrogen, CA) respectively. The cDNA was synthesized using SuperScript VILO cDNA Synthesis Kit (Invitrogen, CA). Quantitative real-time PCR was performed using the SYBR Green PCR master mix kit (Invitrogen, CA) with the intron-spanning primers on ABI-Prism-7900 Sequence Detection System (Applied Biosystems). The PCR primer sets for mouse TXNIP are: (forward) 5'-ATCCCAGATACCCCA GAAGC-3'; (reverse) 5' 5 $^{\prime}$-TAGAGTCGTCCACATCGTC-3' and for mouse $\beta$-actin are: (forward) $5^{\prime}$ - CAGCTGAGAGGG AAATCGTG-3'; (reverse) 5'-CGTTGCCAATAGTGATGACC-3' . The relative mRNA expression levels were calculated according to the $2^{-\Delta \Delta \mathrm{Ct}}$ method. ${ }^{27}$ The mRNA expression of $\beta$-actin was used as endogenous reference control.

\section{Indirect Immunofluorescence}

For indirect immunofluorescence, cells cultured on glass coverslips were washed with PBS, fixed with $4 \%$ formal-
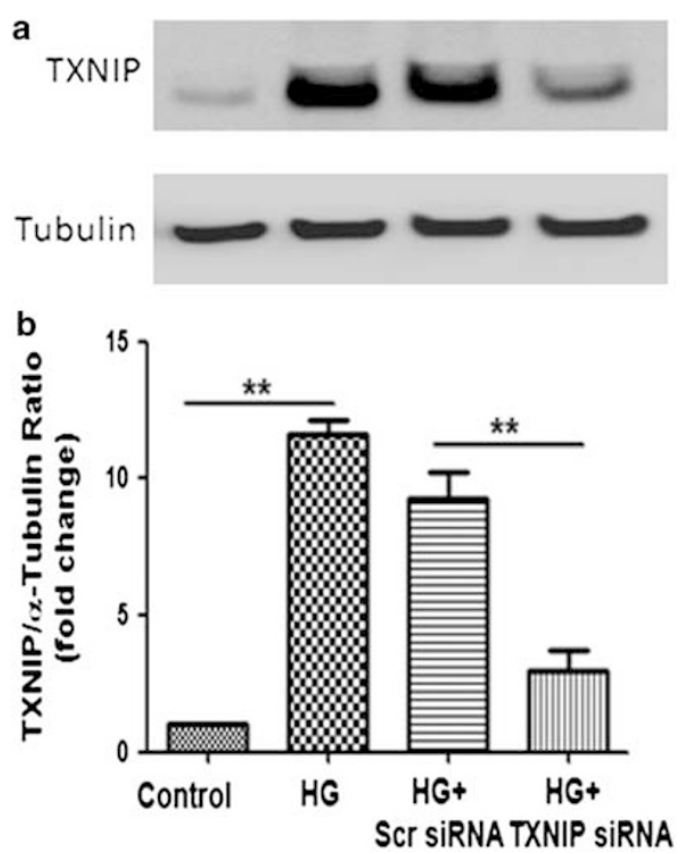

Figure 4 The expression of TXNIP in HG-induced HK2 cells. HK2 cells transfected with scramble siRNA or TXNIP-specific siRNA were untreated or treated with high glucose for $48 \mathrm{~h}$. (a) Immunoblot analysis of TXNIP with or without TXNIP siRNA transfection in HG-induced HK2 cells. (b) Quantification of TXNIP expression in HG-induced HK2 cells. Results are presented as mean + s.e.m. ${ }^{* *} P<0.01 . N=4$. dehyde at room temperature for $15 \mathrm{~min}$, washed with PBS once for $5 \mathrm{~min}$, then permeabilized in $0.3 \%(0.2-0.5 \%)$ Triton X-100 in PBS for $10 \mathrm{~min}$, and blocked with 2\% bovine serum albumin (BSA) in PBS for $1 \mathrm{~h}$ at room temperature. Cells were incubated with primary antibodies anti-rabbitLC3 (1:200), anti-rabbit-p62 (1:100), and anti-rabbitnitrotyrosine $(1: 100)$ in $2 \%$ BSA in PBS overnight at $4{ }^{\circ} \mathrm{C}$. After washing with PBS, cells were incubated with secondary anti-rabbit Alexa Fluor-488 (1:1000, Invitrogen) for $40 \mathrm{~min}$ at room temperature. Cells were then washed with PBS and counterstained with DAPI-mounting medium (Invitrogen). The immunofluorescence images were collected by confocal fluorescence microscopy (Leica Microsystems, Mannheim, Germany).

\section{Western Blot}

Equal amount of cell lysates samples were separated by SDSPAGE, and then transferred to Hybond ECL nitrocellulose membrane (Amersham, USA). The membranes were incubated with primary antibodies anti-rabbit-LC3 (1:500), anti-rabbit-p62 (1:500), and anti-rabbit-TXNIP (1:500) at $4{ }^{\circ} \mathrm{C}$ overnight followed with HRP-conjugated secondary antibody (Amersham, USA) (1:5000). The blots were then detected with standard ECL technique, and the bands were quantified by densitometry using LAS-4000 Imaging System (FUJIFILM, Japan).

\section{Statistical Analysis}

Results from at least four independent experiments were expressed as mean \pm s.e.m. Statistical analysis of data from two groups was compared by two-tailed $t$-test. Analysis of data from multiple groups was performed by one-way ANOVA, followed by Tukey's post test. Statistical significance was determined as $P<0.05$.

\section{RESULTS \\ The Formation of Autophagosomes in Diabetic C57B/6 Mice}

We examined the autophagic marker (LC3) in kidney of diabetic mice after 24 weeks of STZ induction. We have previously described that this animal model develops renal dysfunction and diabetes-induced tubulointerstitial injury. ${ }^{28,29}$ The formation of autophagosomes was determined by LC3 expression, which participates in the initiation and elongation processes of autophagosomes, using indirect immunofluorescence staining. As shown in Figure 1, there is basal expression of LC3 in the kidneys of normal animals, which was increased in the diabetic mice $(P<0.05)$. This accumulation of autophagosomes in diabetic mice may be caused by either induction of autophagy or inhibition of autophagosome clearance and/or degradation of autophagic substrates in the lysosome.

\section{Autophagic Flux in Diabetic Mice}

To determine tubular autophagic flux in diabetic mouse, the autophagosome clearance was examined with p62, a selective substrate of autophagy. Immunofluorescence, segmental 

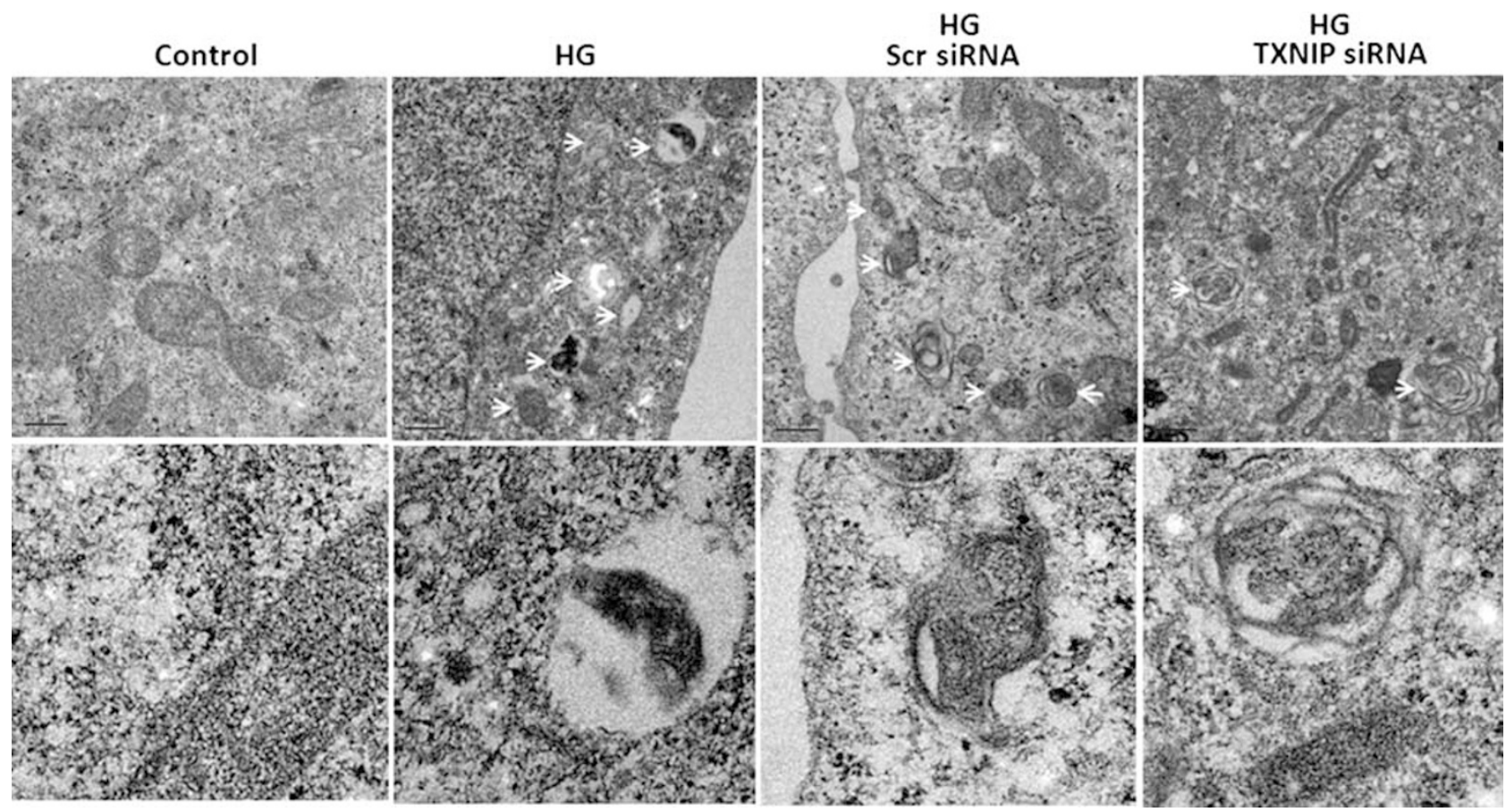

Figure 5 Electron microscopic evaluation of autophagy in HG-induced HK2 cells. HK2 cells transfected with scramble siRNA or TXNIP-specific siRNA were treated with high glucose for $48 \mathrm{~h}$. In the upper panel, representative electron micrographs show autophagic vacuoles indicated by white arrows in HK2 cells $(\times 5000)$. In the lower panel, higher magnification $(\times 10000)$ of electron micrographs show the structure of single autophagosomes or autolysosomes from upper panels.

labeling of p62 was observed, mainly in proximal tubules (Figure 2). Consistent with the LC3 findings, p62 staining was significantly increased in diabetic mice as compared with non-diabetic controls $(P<0.01$, Figure 2). Collectively, the increase of LC3 and p62 indicate the accumulation of autophagosomes due to the suppression of autophagic flux in the proximal tubules of diabetic mice.

\section{Overexpression of TXNIP in Diabetic Mice}

Our group and others have reported that elevated TXNIP expression contributes to the oxidative stress reported in diabetic nephropathy. ${ }^{19,20}$ To determine whether TXNIP has a role in regulation of autophagy, we first examined the expression of TXNIP in the diabetic and control mice. RT-PCR analyses of kidney tissues demonstrated increased mRNA expression of TXNIP in the diabetic group compared with control mice $(P<0.05$, Figure $3 \mathrm{a})$, and histopathological analysis of renal cross-sections demonstrated increase of TXNIP protein significantly in diabetic mice compared with controls $(P<0.01$, Figures $3 \mathrm{~b}$ and $\mathrm{c})$. These data confirmed that TXNIP expression was upregulated in kidney of diabetic mice.

\section{TXNIP Gene Silence Reversed HG-Induced Suppression of Autophagic Flux}

To further investigate whether TXNIP is involved in the regulation of tubular autophagy in diabetes, in vitro studies were undertaken where tubular cells were exposed to HG and TXNIP was silenced using TXNIP siRNA. The inhibitory effect was determined by western blotting. As shown in Figure 4, the inhibitory efficiency is approximately $70 \%$.

To confirm HG-induced dysfunction of autophagy and the effect of TXNIP on autophagy in kidney tubular cells, we examined autophagy using transmission electron microscopy, and the appearance of autophagosomes and related autophagic vacuoles was monitored. As shown in Figure 5 (upper panel), no obvious autophagic vacuoles were shown in HK2 cells exposed to normal glucose. However, several autophagic vacuoles appeared in HK2 cells with/without scramble siRNA transfection exposed to HG for $48 \mathrm{~h}$ but much fewer autophagic vacuoles were observed in HK2 cells with TXNIP siRNA transfection exposed to HG for $48 \mathrm{~h}$. The structures of autophagic vacuoles were shown by higher magnification $(\times 10000)$ electron microscopy (lower panel in Figure 5).

Consistently, western blotting results showed that the level of LC3-II is significantly increased in HK2 cells exposed to HG, while TXNIP silencing suppressed the HG-induced LC3-II expression $(P<0.01$, Figures 6a and b). Immunofluorescence staining further confirmed the HG-induced LC3, which was reversed by TXNIP silencing $(P<0.01$, Figures $6 c$ and d). Similarly, HG-induced p62 expression was also abrogated by TXNIP silencing, confirmed by western blotting and immunofluorescence staining $(P<0.01$, Figures $7 \mathrm{a}-\mathrm{d})$. 
a
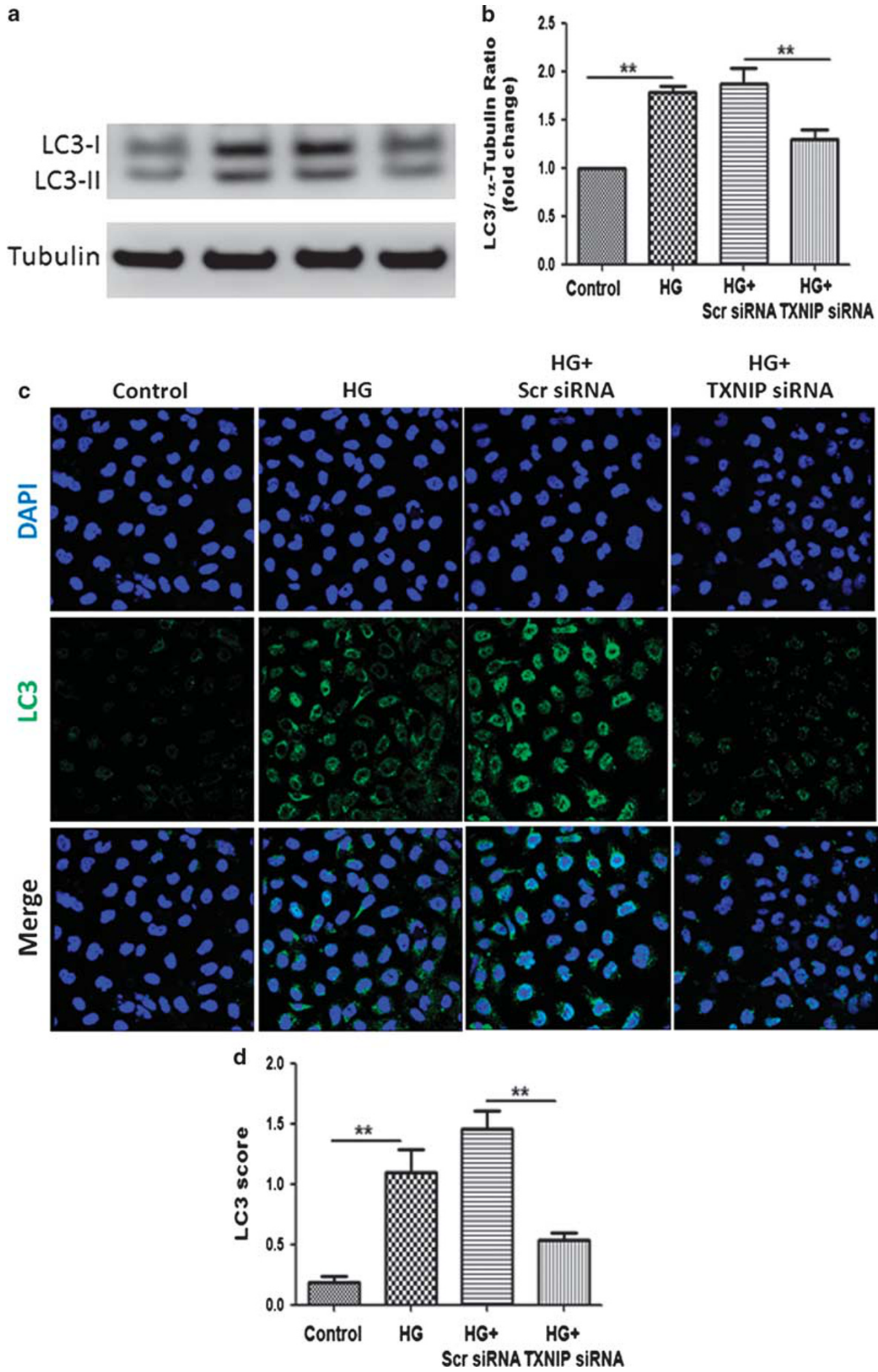

Figure 6 Effect of knockdown TXNIP on the expression of LC3 in HG-induced HK2 cells. HK2 cells transfected with scramble siRNA or TXNIP-specific siRNA were untreated or treated with high glucose for $48 \mathrm{~h}$. (a) Immunoblot analysis of LC3 with or without TXNIP siRNA transfection in HG-induced HK2 cells. (b) Quantification of LC3 immunoblot expression in HG-induced HK2 cells. (c) Immunofluorescence staining of LC3 in HG-induced HK2 cells transfected with or without TXNIP siRNA. (d) Quantification of LC3 immunofluorescence expression in HG-induced HK2 cells. Results are presented as mean + s.e.m. ${ }^{* *} P<0.01 . N=4$. Original magnification: $\times 600$. 
a

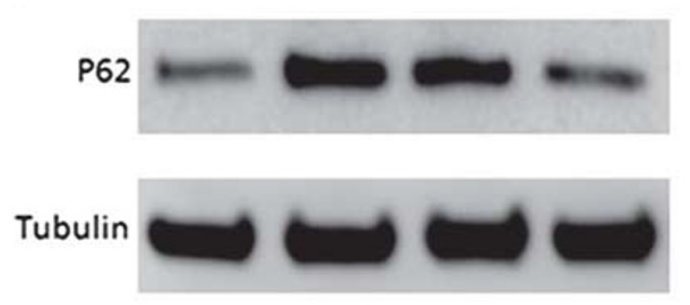

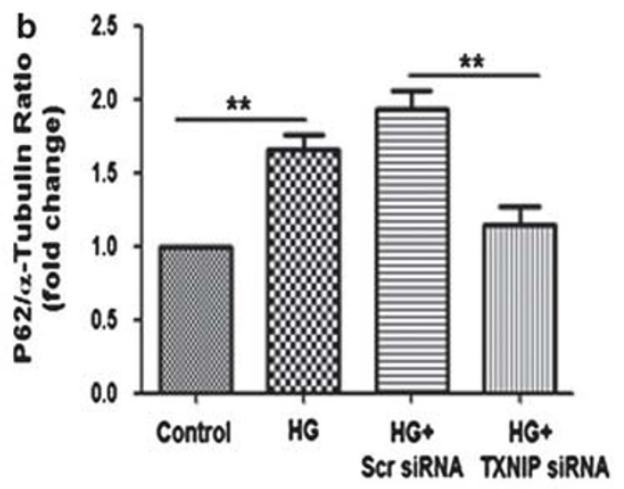

HG+ Scr SIRNA

c

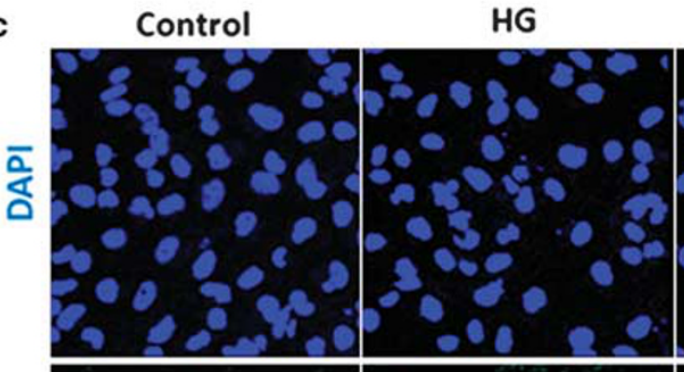

HG+ TXNIP SIRNA

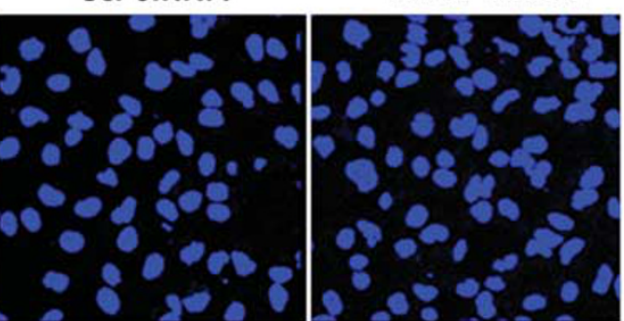

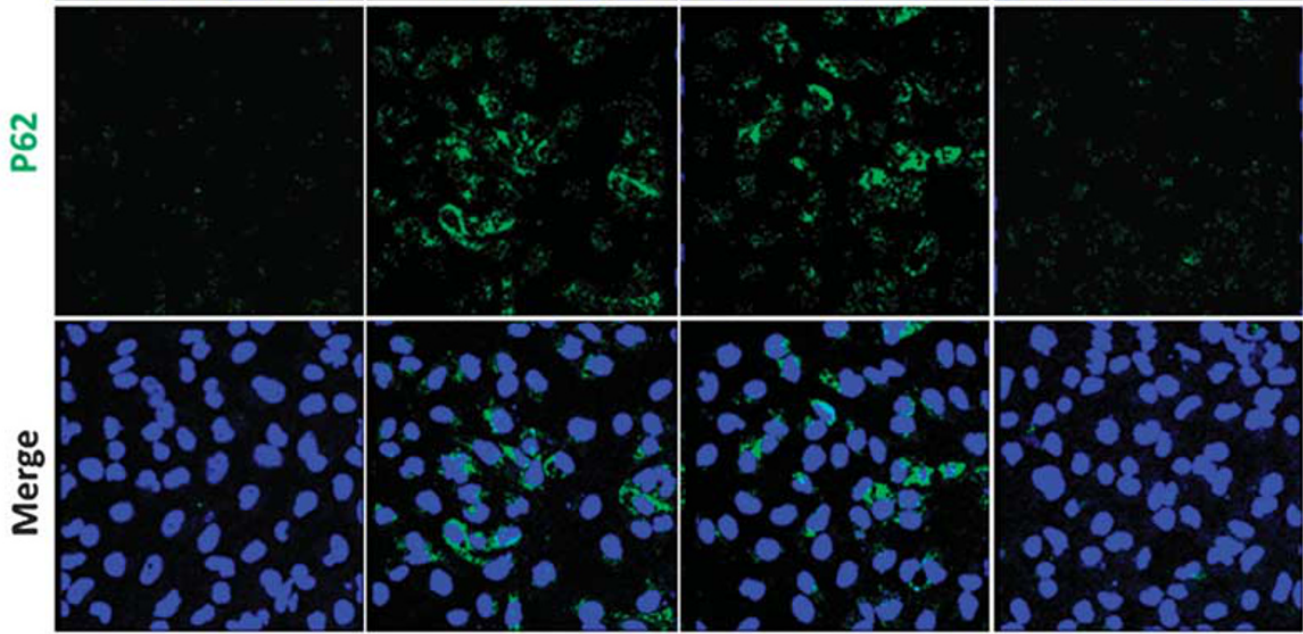

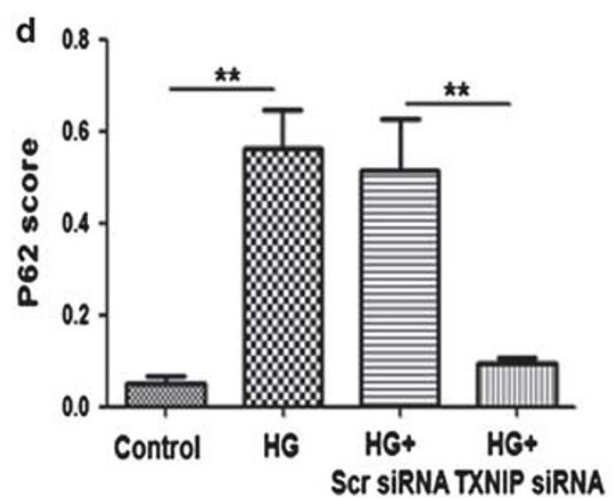

Figure 7 Effect of knockdown TXNIP on the expression of p62 in HG-induced HK2 cells. HK2 cells transfected with scramble siRNA or TXNIP-specific siRNA were untreated or treated with high glucose for $48 \mathrm{~h}$. (a) Immunoblot analysis of p62 with or without TXNIP siRNA transfection in HG-induced HK2 cells. (b) Quantification of p62 immunoblot expression in HG-induced HK2 cells. (c) Immunofluorescence staining of p62 in HG-induced HK2 cells transfected with or without TXNIP siRNA. (d) Quantification of p62 immunofluorescence expression in HG-induced HK2 cells. Results are presented as mean \pm s.e.m. ${ }^{*} P<0.01 . N=4$. Original magnification: $\times 600$. 

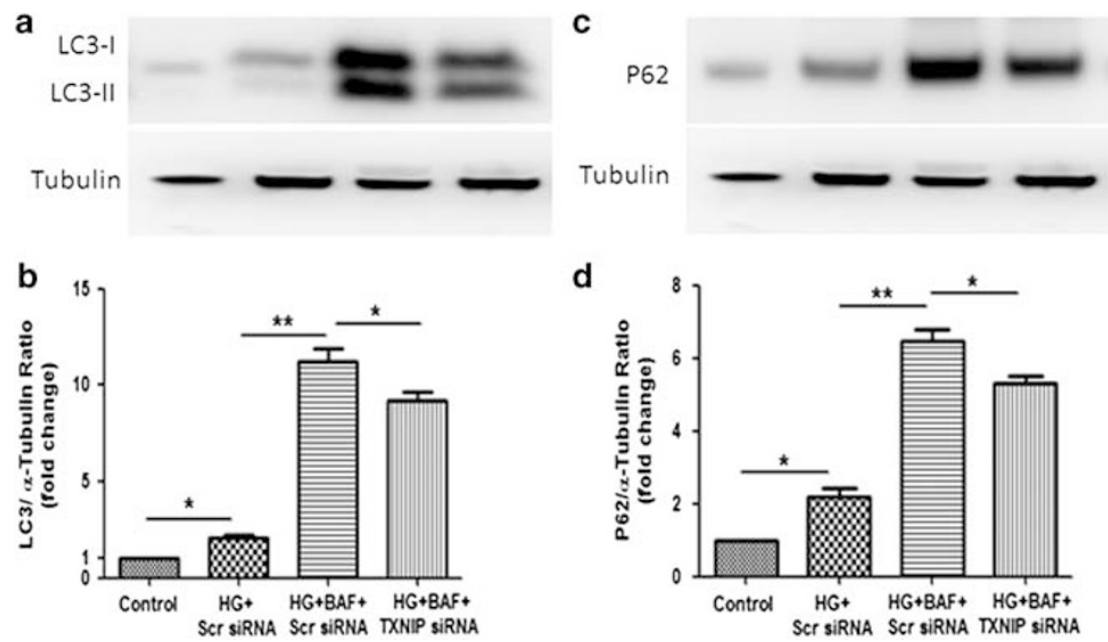

Figure 8 Effect of knockdown TXNIP on the expression of LC3 and p62 in HG-induced HK2 cells together with or without bafilomycin A1. HK2 cells transfected with scramble siRNA or TXNIP-specific siRNA overnight were pretreated with $50 \mathrm{nmol} / \mathrm{l}$ bafilomycin $\mathrm{A}_{1}$ for $3 \mathrm{~h}$ and then incubated with HG $(30 \mathrm{mM})$ together for $48 \mathrm{~h}$. Immunoblot analysis of LC3 (a) and p62 (c) with or without TXNIP siRNA transfection in HG-induced HK2 cells together with bafilomycin $A_{1}$. Quantification of LC3 (b) and p62 (d) expression in HG-induced HK2 cells together with bafilomycin $A_{1}$. Results are presented as mean + s.e.m. ${ }^{*} P<0.05$ and ${ }^{*} P<0.01 . N=4$.

\section{Bafilomycin $A_{1}$-Induced Blockade of Autophagic Flux was Partially Reversed by TXNIP Gene Silencing in PTCs In Vitro}

To address whether TXNIP mediates HG-induced dysregulation of tubular autophagy, we tested the effect of bafilomycin $\mathrm{A}_{1}$, a pharmacological inhibitor of autophagy, in renal tubular cells with or without TXNIP silencing. As shown in Figure 8a, HG significantly increased the level of LC3-II as compared with control group. Treatment with bafilomycin $\mathrm{A}_{1}$ further increased the level of LC3 in HK2 cells exposed to HG, which is partially reversed by TXNIP gene silencing $(P<0.05$, Figure $8 \mathrm{~b})$. In line with these findings, the level of p62 protein was significantly increased in HG-induced HK2 cells. Treatment with bafilomycin $A_{1}$ further increased the level of p62 in HG-induced HK2 cells as well, which is partially reversed by TXNIP gene silencing $(P<0.05$, Figures $8 \mathrm{c}$ and $\mathrm{d}$ ). These data indicate that TXNIP is involved in the regulation of tubular autophagy under HG conditions.

\section{TXNIP Mediates HG-Induced Dysfunction of Tubular Autophagy through Oxidative Stress}

TXNIP is an endogenous inhibitor of the anti-oxidant thioredoxin and is highly upregulated in diabetic nephropathy, leading to oxidative stress and fibrosis. ${ }^{17}$ Recently, it has been reported that autophagy is modulated by multiple intracellular stresses, including oxidative stress. ${ }^{30,31}$ To investigate whether TXNIP-mediated oxidative stress is involved in regulation of autophagy, nitrotyrosine, ${ }^{32}$ a marker of NO-dependent oxidative stress, was examined in diabetic mice kidneys. Immnunohistochemical staining results confirmed that the expression of nitrotyrosine is significantly increased in diabetic mice compared with non-diabetic mice $(P<0.05$, Figures $9 \mathrm{a}$ and $\mathrm{b})$. Furthermore, we examined the expression of nitrotyrosine in HG-induced HK2 cells in vitro. As shown in Figures 9c and d, HG significantly increased the expression of nitrotyrosine in HK2 cells that was reversed by TXNIP silencing $(P<0.01)$. Together, these results indicate that HG-induced overexpression of TXNIP is likely to mediate dysregulation of tubular autophagy through oxidative stress.

\section{DISCUSSION}

The present study was conducted to investigate the dysregulation of autophagy in tubular cells in a validated mouse model of diabetic nephropathy ${ }^{29}$ and in cultured human PTCs exposed to HG. The results demonstrate increased formation of autophagosomes and reduced autophagic clearance in renal tubular cells under diabetic conditions. Furthermore, silencing of the TXNIP gene, using siRNA technology, reduced formation of autophagosomes and promoted autophagic clearance in tubular cells exposed to HG. TXNIP gene silencing also partially reversed bafilomycin $\mathrm{A}_{1}$-induced blockade of autophagosome clearance.

Established evidence indicates that the renal proximal tubular epithelial cell has a central role in the pathogenesis of diabetic nephropathy, and renal function closely correlates with the degree of tubulointerstitial injury rather than the glomerular pathology. $7,8,33,34$ Proximal tubular epithelial cells have an important role in the reabsorption and degradation of albumin and low-molecular-weight plasma proteins from the glomerular filtrate..$^{35}$ Numerous studies have reported on autophagy of PTCs in models of acute renal injury. Autophagy is readily induced by renal ischemia-reperfusion ${ }^{2,3}$ and cisplatin damage to the kidneys. ${ }^{2,36}$ Reduced autophagic activity worsens acute kidney injury, ${ }^{2,4,37}$ suggesting that stress-inducible autophagy is renoprotective. To date, dysre- 
a

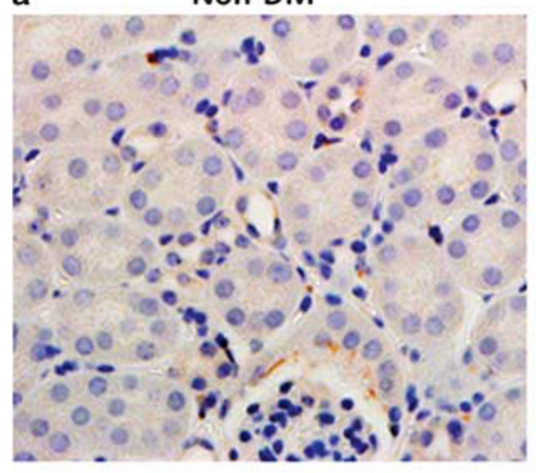

c
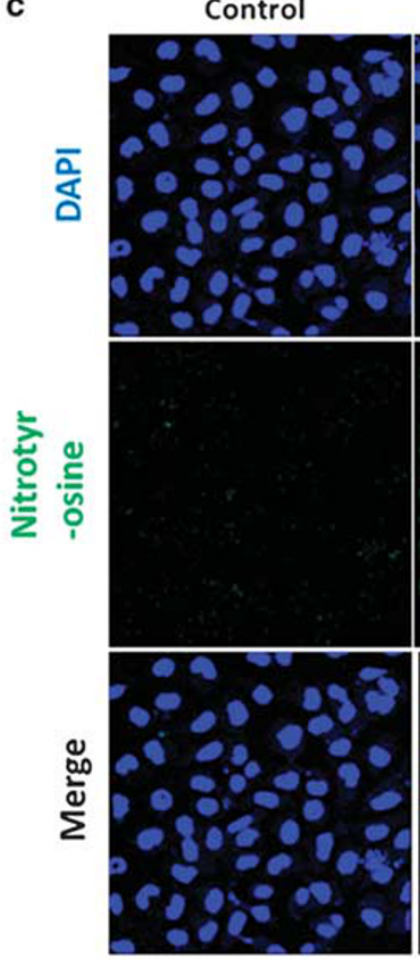

DM

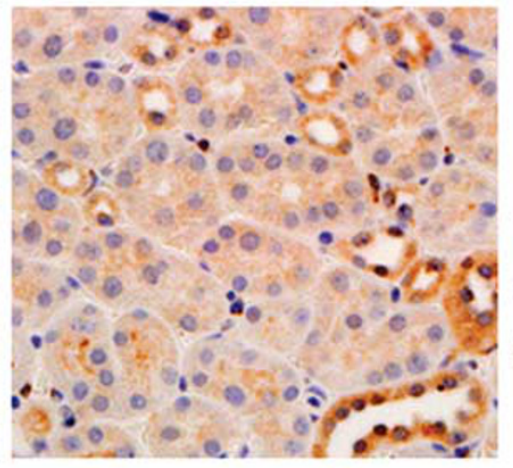

HG+

HG

Scr SiRNA
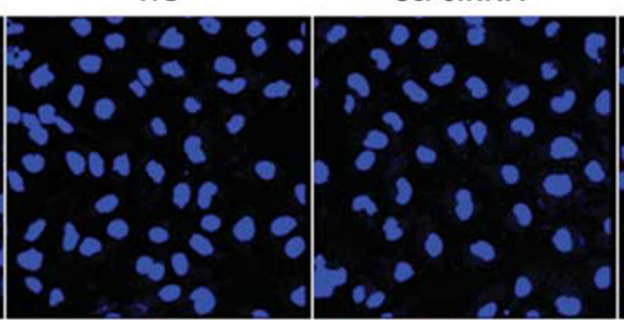

HG+

TXNIP SIRNA
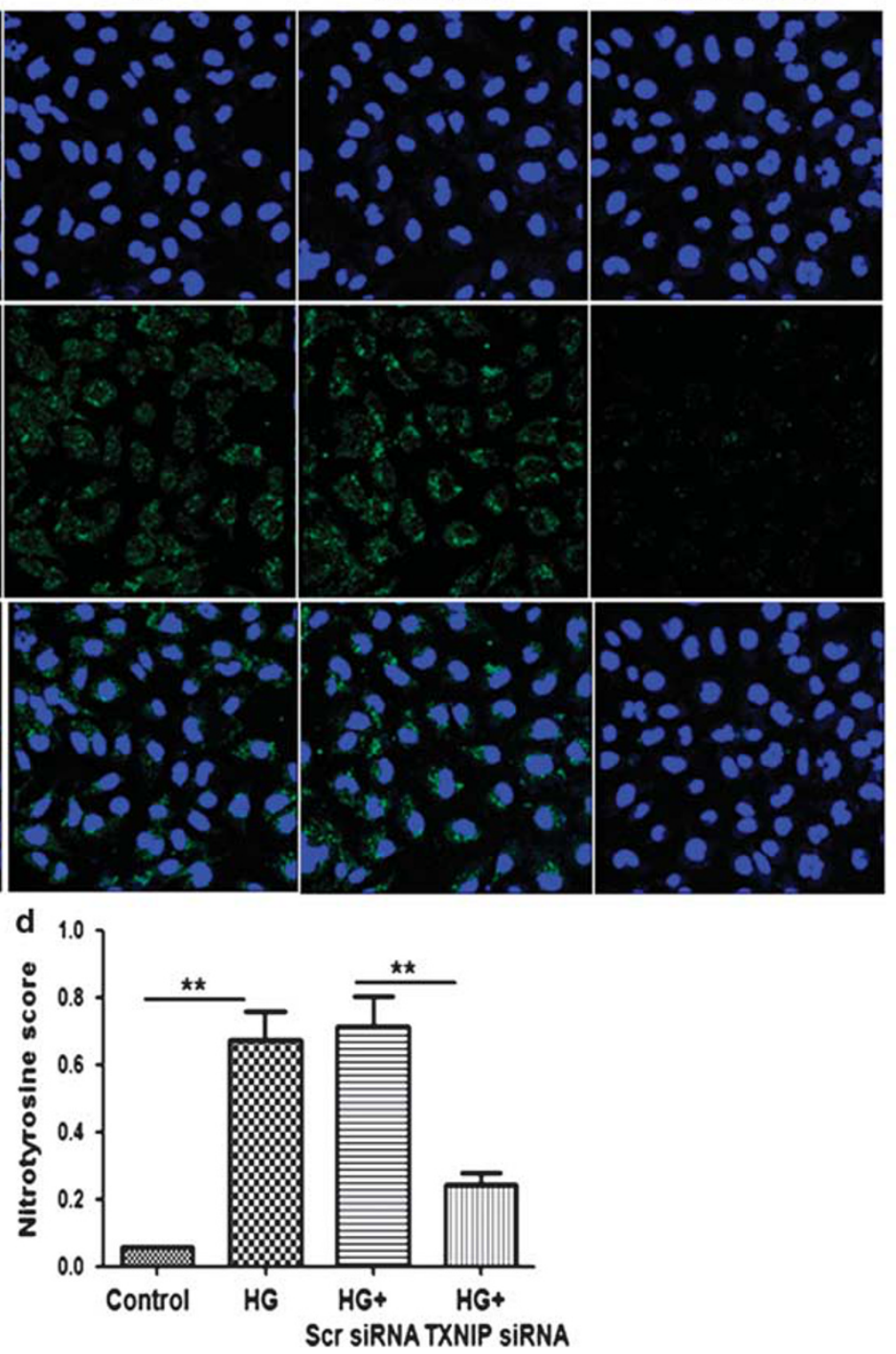

Figure 9 The expression of nitrotyrosine in diabetic mice tissues and effect of knockdown TXNIP on the expression of nitrotyrosine in HG-induced HK2 cells. C57B/6 mice were injected with STZ to induce diabetes or citrate buffer alone as non-diabetic control. After 24 weeks diabetes, kidney tissues were collected for immnostaining. (a) Immunohistochemical staining of nitrotyrosine in mice kidney tissues. $N=8$. (b) Quantification of nitrotyrosine expression in mice kidney tissues. HK2 cells transfected with scramble siRNA or TXNIP-specific siRNA were untreated or treated with high glucose for $48 \mathrm{~h}$. (c) Immunofluorescence staining of nitrotyrosine in HG-induced HK2 cells transfected with or without TXNIP siRNA. (d) Quantification of nitrotyrosine expression in HG-induced HK2 cells. Results are presented as mean \pm s.e.m. ${ }^{* *} P<0.01 . N=4$. Original magnification: $\times 600$. 
gulation of tubular autophagy in kidney under diabetic conditions has not been reported.

To investigate whether chronic hyperglycemia leads to dysfunction of tubular autophagy, we initially examined the expression of LC3 and p62 in tubular cells of fibrotic kidneys. It is well documented that LC3 and p62 undergo post-translational modifications in the autophagy machinery. ${ }^{38-42}$ The lipidation of LC3 by the phospholipid phosphatidylethanolamine to forms LC3-II associates with forming autophagosome membranes and the conversion of LC3 to LC3-II is well accepted as a marker of autophagy induction, and p62 protein degraded by autophagy inversely reflects the autophagic flux, therefore the protein levels of LC3-II and p62 were examined to monitor autophagy and autophagic flux in this study. ${ }^{21,22,26,43-46}$ We found significantly increased expression of LC3 and p62 in diabetic kidneys compared with non-diabetic controls (Figures 1 and 2). The quantitative and meaningful assay for examining autophagy is the measurement of autophagosome formation. ${ }^{21,44}$ To date, LC3-II is the only well-characterized protein that is specifically localized to autophagic structures throughout the process from phagophore to lysosomal degradation. ${ }^{21,22}$ However, increased LC3-II levels can be associated with either enhanced autophagosome synthesis or reduced autophagosome clearance. ${ }^{21,44}$ To better interpret the changes in the levels of processed LC3-II, p62 protein levels are required. p62 possesses a short LC3 interaction region that facilitates direct interaction with LC3 and causes $\mathrm{p} 62$ to be specifically degraded by autolysosomes. ${ }^{43}$ If autophagy flux is not completed, p62 is not degraded, and elevations in p62 characterize impaired autophagy flux. ${ }^{43,47}$ Hence, the expression of p62 is inversely correlated with autophagic flux. Thus our results indicate the inhibition of autophagic flux in diabetic kidney of mice.

To confirm whether hyperglycemia directly affects the clearance of autophagosome in renal tubular cells, the expression of LC3-II and p62 and autophagic vacuoles were measured in human PTCs exposed to HG $(30 \mathrm{mM} / \mathrm{l})$ for $48 \mathrm{~h}$ using western blotting and transmission electron microscope, which have been accepted as classic approach to define the stage of autophagy and its process in tissue and cell. ${ }^{21,26,44}$ The results (Figures 5-7) are consistent with our findings in diabetic kidneys. TXNIP expression is ubiquitous and is induced by a variety of cellular stresses, including high intracellular glucose. ${ }^{14}$ We previously demonstrated that TXNIP was the gene most significantly increased in human proximal tubule cells exposed to $\mathrm{HG}{ }^{18}$ which was confirmed in kidneys of diabetic mice compared with controls (Figure 3) and in humans with diabetic nephropathy. ${ }^{19,20}$ As HG induced expression of TXNIP and suppressed autophagic flux in renal tubular cells, the link between TXNIP and autophagy in renal tubular cells was characterized. Our results demonstrated that HG-induced expression of LC3-II and p62 and accumulation of autophagic vacuoles were decreased significantly in TXNIP gene-silenced renal tubular cells exposed to HG (Figures 5-7). These data suggested that
TXNIP gene knockdown promoted tubular autophagosome clearance, which was inhibited by HG. Bafilomycin $A_{1}$ is a specific inhibitor of the vacuolar type $\mathrm{H}+$-ATPase (V-ATPase) in cells and inhibits the acidification of organelles, including lysosomes. Bafilomycin $A_{1}$ is widely used to assess autophagic flux, because inhibition of either fusion with the lysosome or hydrolase activity will impair degradation of LC3-II. ${ }^{21,44,48}$ To further define whether TXNIP affects tubular autophagosome clearance, LC3-II and p62 expression were measured in TXNIP gene-silenced renal tubular cells exposed to bafilomycin $A_{1}$. Our results demonstrated that TXNIP gene silencing partially reversed bafilomycin $A_{1}$-induced blockade of renal tubular autophagic flux (Figure 8).

Oxidative stress results from excessive production or accumulation of ROS. ROS-induced cellular oxidative stress is a major modulator of autophagy. However, autophagy is also able to regulate the formation of ROS. ${ }^{1,49}$ A large body of evidence indicates that ROS have a major role in the development of diabetic nephropathy. ${ }^{50-52}$ TXNIP binds to the active cysteine residue of thioredoxin (TRX) and inhibits its antioxidative function. Hence, the TRX/TXNIP system has a major role in regulation of cellular redox homeostasis. ${ }^{6}$ Our results confirm the association of increased TXNIP expression with oxidative stress in diabetic kidneys and PTCs exposed to HG. The effect of TXNIP in inducing dysregulated autophagy is confirmed by partially reversed oxidative stress in cells with TXNIP gene silencing (Figure 9). Together, these data further confirm the critical role of TXNIP on renal tubular autophagy.

In summary, our studies provide evidence that tubular autophagic flux is disrupted in diabetic nephropathy and links the overexpression of TXNIP to the dysregulation of tubular autophagy. This finding suggests that maintenance of tubular autophagy through inhibition of TXNIP may be a potential therapeutic strategy in limiting diabetic nephropathy.

\section{ACKNOWLEDGMENTS}

We acknowledge the facilities as well as the scientific and technical assistance from staff of the AMMRF (Australian Microscopy and Microanalysis Research Facility) at the Australian Centre for Microscopy and Microanalysis, the University of Sydney, Sydney, NSW, Australia.

\section{DISCLOSURE/CONFLICT OF INTEREST}

The authors declare no conflict of interest.

1. Ravikumar B, Sarkar S, Davies JE, et al. Regulation of mammalian autophagy in physiology and pathophysiology. Physiol Rev 2010;90: 1383-1435.

2. Jiang M, Wei Q, Dong G, et al. Autophagy in proximal tubules protects against acute kidney injury. Kidney Int 2012;82:1271-1283.

3. Kimura T, Takabatake Y, Takahashi A, et al. Autophagy protects the proximal tubule from degeneration and acute ischemic injury. J Am Soc Nephrol 2011;22:902-913.

4. Liu S, Hartleben B, Kretz O, et al. Autophagy plays a critical role in kidney tubule maintenance, aging and ischemia-reperfusion injury. Autophagy 2012;8:826-837. 
5. Hartleben B, Godel M, Meyer-Schwesinger C, et al. Autophagy influences glomerular disease susceptibility and maintains podocyte homeostasis in aging mice. J Clin Invest 2010;120:1084-1096.

6. Fang L, Zhou Y, Cao H, et al. Autophagy attenuates diabetic glomerular damage through protection of hyperglycemia-induced podocyte injury. PLoS One 2013;8:e60546.

7. Tang SC, Leung JC, Lai KN. Diabetic tubulopathy: an emerging entity. Contrib Nephrol 2011;170:124-134.

8. Tang SC, Lai KN. The pathogenic role of the renal proximal tubular cell in diabetic nephropathy. Nephrol Dial Transplant 2012;27:3049-3056.

9. Calcutt NA, Cooper ME, Kern TS, et al. Therapies for hyperglycaemiainduced diabetic complications: from animal models to clinical trials. Nat Rev Drug Discov 2009;8:417-429.

10. D'Agati V, Schmidt AM. RAGE and the pathogenesis of chronic kidney disease. Nat Rev Nephrol 2010;6:352-360.

11. Decleves $A E$, Sharma K. New pharmacological treatments for improving renal outcomes in diabetes. Nat Rev Nephrol 2010;6:371-380.

12. Ruggenenti $P$, Cravedi $P$, Remuzzi $G$. The RAAS in the pathogenesis and treatment of diabetic nephropathy. Nat Rev Nephrol 2010;6:319-330.

13. Junn E, Han SH, Im JY, et al. Vitamin D3 up-regulated protein 1 mediates oxidative stress via suppressing the thioredoxin function. J Immunol 2000;164:6287-6295.

14. Minn AH, Hafele C, Shalev A. Thioredoxin-interacting protein is stimulated by glucose through a carbohydrate response element and induces beta-cell apoptosis. Endocrinology 2005;146:2397-2405.

15. Saxena G, Chen J, Shalev A. Intracellular shuttling and mitochondrial function of thioredoxin-interacting protein. J Biol Chem 2010;285: 3997-4005.

16. Zhang Y, Yuen DA, Advani A, et al. Early-outgrowth bone marrow cells attenuate renal injury and dysfunction via an antioxidant effect in a mouse model of type 2 diabetes. Diabetes 2012;61:2114-2125.

17. Tan SM, Zhang Y, Cox AJ, et al. Tranilast attenuates the up-regulation of thioredoxin-interacting protein and oxidative stress in an experimental model of diabetic nephropathy. Nephrol Dial Transplant 2011;26:100-110.

18. Qi W, Chen X, Gilbert RE, et al. High glucose-induced thioredoxininteracting protein in renal proximal tubule cells is independent of transforming growth factor-beta1. Am J Pathol 2007;171:744-754.

19. Advani A, Gilbert RE, Thai K, et al. Expression, localization, and function of the thioredoxin system in diabetic nephropathy. J Am Soc Nephrol 2009;20:730-741.

20. Qi W, Chen X, Holian J, et al. Transcription factors Kruppel-like factor 6 and peroxisome proliferator-activated receptor-\{gamma\} mediate high glucose-induced thioredoxin-interacting protein. Am J Pathol 2009;175:1858-1867.

21. Barth S, Glick D, Macleod KF. Autophagy: assays and artifacts. J Pathol 2010;221:117-124.

22. Nakatogawa H, Suzuki K, Kamada $\mathrm{Y}$, et al. Dynamics and diversity in autophagy mechanisms: lessons from yeast. Nat Rev Mol Cell Biol 2009;10:458-467.

23. Tesch GH. Role of macrophages in complications of type 2 diabetes. Clin Exp Pharmacol Physiol 2007;34:1016-1019.

24. Doi $\mathrm{S}$, Zou $\mathrm{Y}$, Togao $\mathrm{O}$, et al. Klotho inhibits transforming growth factor-beta1 (TGF-beta1) signaling and suppresses renal fibrosis and cancer metastasis in mice. J Biol Chem 2011;286:8655-8665.

25. Kobayashi K, Cheng D, Huynh M, et al. Imaging fluorescently labeled complexes by means of multidimensional correlative light and transmission electron microscopy: practical considerations. Methods Cell Biol 2012;111:1-20.

26. Yla-Anttila $P$, Vihinen $H$, Jokitalo $E$, et al. Monitoring autophagy by electron microscopy in Mammalian cells. Methods Enzymol 2009;452: 143-164.

27. Livak KJ, Schmittgen TD. Analysis of relative gene expression data using real-time quantitative PCR and the 2(T)(-Delta Delta C) method. Methods 2001;25:402-408.
28. Huang $\mathrm{C}$, Shen $\mathrm{S}, \mathrm{Ma} \mathrm{Q}$, et al. Blockade of KCa3.1 ameliorates renal fibrosis through the TGF-beta1/Smad pathway in diabetic mice. Diabetes 2013;62:2923-2934.

29. Huang C, Shen S, Ma Q, et al. KCa3.1 mediates activation of fibroblasts in diabetic renal interstitial fibrosis. Nephrol Dial Transplant advance online publication, 4 December 2013 (in press).

30. Koya D, Hayashi K, Kitada M, et al. Effects of antioxidants in diabetes induced oxidative stress in the glomeruli of diabetic rats. J Am Soc Nephrol 2003;14(8 Suppl 3):S250-S253.

31. Brezniceanu ML, Liu F, Wei CC, et al. Catalase overexpression attenuates angiotensinogen expression and apoptosis in diabetic mice. Kidney Int 2007;71:912-923.

32. Pacher P, Obrosova IG, Mabley JG, et al. Role of nitrosative stress and peroxynitrite in the pathogenesis of diabetic complications. Emerging new therapeutical strategies. Curr Med Chem 2005;12:267-275.

33. Phillips $\mathrm{AO}$. The role of renal proximal tubular cells in diabetic nephropathy. Curr Diab Rep 2003;3:491-496.

34. Phillips AO, Steadman R. Diabetic nephropathy: the central role of renal proximal tubular cells in tubulointerstitial injury. Histol Histopathol 2002;17:247-252.

35. Maack T, Johnson V, Kau ST, et al. Renal filtration, transport, and metabolism of low-molecular-weight proteins: a review. Kidney Int 1979;16:251-270.

36. Periyasamy-Thandavan $\mathrm{S}$, Jiang $\mathrm{M}$, Wei $\mathrm{Q}$, et al. Autophagy is cytoprotective during cisplatin injury of renal proximal tubular cells. Kidney Int 2008;74:631-640.

37. Takahashi A, Kimura T, Takabatake Y, et al. Autophagy guards against cisplatin-induced acute kidney injury. Am J Pathol 2012;180:517-525.

38. Bjorkoy G, Lamark T, Brech A, et al. p62/SQSTM1 forms protein aggregates degraded by autophagy and has a protective effect on huntingtin-induced cell death. J Cell Biol 2005;171:603-614.

39. Kabeya $\mathrm{Y}$, Mizushima N, Ueno $\mathrm{T}$, et al. LC3, a mammalian homologue of yeast Apg8p, is localized in autophagosome membranes after processing. EMBO J 2000;19:5720-5728.

40. Kabeya Y, Mizushima N, Yamamoto A, et al. GABARAP and GATE16 localize to autophagosomal membrane depending on form-II formation. J Cell Sci 2004;117(Pt 13):2805-2812

41. Tanida I, Ueno T, Kominami E. LC3 conjugation system in mammalian autophagy. Int J Biochem Cell Biol 2004;36:2503-2518.

42. Vadlamudi RK, Joung I, Strominger JL, et al. p62, a phosphotyrosineindependent ligand of the $\mathrm{SH} 2$ domain of p56lck, belongs to a new class of ubiquitin-binding proteins. J Biol Chem 1996;271:20235-20237.

43. Bjorkoy G, Lamark T, Pankiv S, et al. Monitoring autophagic degradation of p62/SQSTM1. Methods Enzymol 2009;452:181-197.

44. Klionsky DJ, Abdalla FC, Abeliovich H, et al. Guidelines for the use and interpretation of assays for monitoring autophagy. Autophagy 2012;8:445-544.

45. Menzies FM, Moreau K, Puri C, et al. Measurement of autophagic activity in mammalian cells. Curr Protoc Cell Biol 2012;Chapter 15:Unit 1516.

46. Tanida I, Waguri S. Measurement of autophagy in cells and tissues. Methods Mol Biol 2010;648:193-214.

47. Komatsu M, Waguri S, Koike M, et al. Homeostatic levels of p62 control cytoplasmic inclusion body formation in autophagy-deficient mice. Cell 2007;131:1149-1163.

48. Klionsky DJ, Elazar Z, Seglen PO, et al. Does bafilomycin A1 block the fusion of autophagosomes with lysosomes? Autophagy 2008;4:849-950.

49. Lee J, Giordano S, Autophagy Zhang J. mitochondria and oxidative stress: cross-talk and redox signalling. Biochem J 2012;441:523-540.

50. $\mathrm{Ha} \mathrm{H}$, Hwang IA, Park JH, et al. Role of reactive oxygen species in the pathogenesis of diabetic nephropathy. Diabetes Res Clin Pract 2008;82(Suppl 1):S42-S45.

51. Ha H, Lee HB. Reactive oxygen species and matrix remodeling in diabetic kidney. J Am Soc Nephrol 2003;14(8 Suppl 3):S246-S249.

52. Kashihara N, Haruna $Y$, Kondeti VK, et al. Oxidative stress in diabetic nephropathy. Curr Med Chem 2010;17:4256-4269. 